\title{
$\mathbf{L}$ e h r b u c h
}

der

\section{Elemente der Geometrie}

u n d

der ebenen und sphärischen

Trigonometrie, vorzüglich

$\mathbf{2} \mathbf{n m}$

Selbstunterrichte;

e $r \begin{gathered}f \text { a } \\ \text { von }\end{gathered}$

Dr. A. L. Crelle,

Königlich - Preufsischem Geheimen - Ober - Banrathe.

Z weiter Band,

welcher

die Stereometrie, sphärische Trigonometrie und Polyëdrometrie e $n$th ä I t.

Mitvierzehn Kuptertatel n.

Berlin, $182 \%$

Gedruckt und verlegt

bei G. Reimer: 
